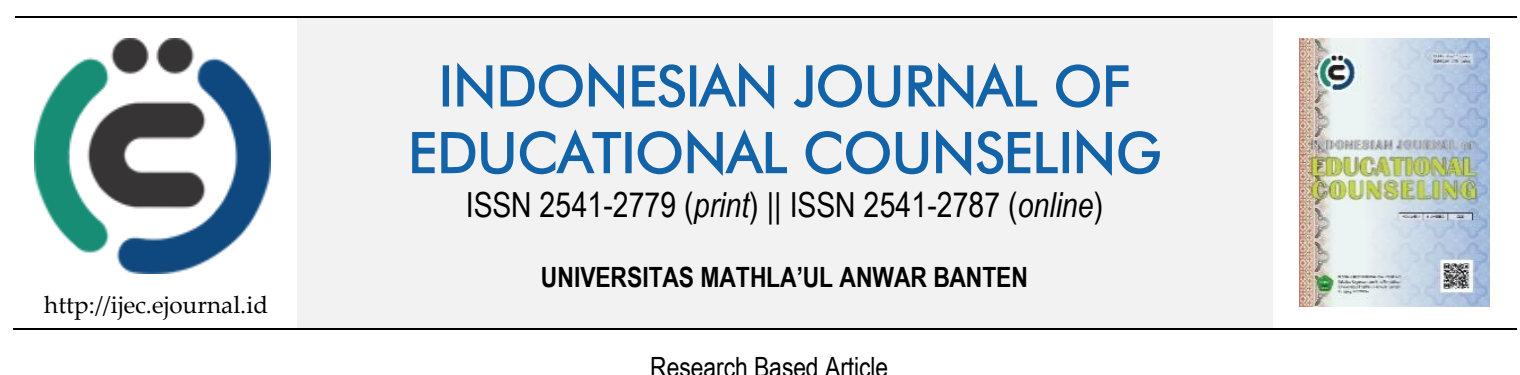

Research Based Article

\title{
Penyesuaian Sosial Remaja Single Sex Schools
}

\author{
Nadia Aulia Nadhirah ${ }^{1}$, Ipah Saripah ${ }^{2}$, Esty Noorbaiti Intani ${ }^{2}$ \\ 1,2 Universitas Pendidikan Indonesia, Indonesia
}

\begin{tabular}{|c|c|}
\hline Article History & ABSTRACT \\
\hline $\begin{array}{l}\text { Received: } 11.02 .2020 \\
\text { Received in revised form: } \\
09.06 .2020 \\
\text { Accepted: } 25.06 .2020 \\
\text { Available online: } 28.07 .2020\end{array}$ & $\begin{array}{l}\text { ADOLESCENT SOCIAL ADJUSTMENT OF SINGLE SEX SCHOOLS. } \\
\text { Teenagers sometimes have the inability to overcome the conflicts they face. This } \\
\text { inability can be seen from the behavior of not finding the right ways to } \\
\text { overcome problems, resolve demands from the environment, unable to build } \\
\text { good relationships with others, hard to believe and be accepted by other people } \\
\text { or their environment. The study aims to determine social adjustment in } \\
\text { adolescent single sex schools which is a practice of learning by dividing } \\
\text { students according to gender, male students are in a classroom with the same } \\
\text { sex, and vice versa. The results of evaluations carried out on single sex schools, } \\
\text { there are several problems that hinder the task of adolescent development, one } \\
\text { of which is the aspect of social adjustment. The study was conducted using a } \\
\text { survey method in class XII students of one of the boarding school high schools } \\
\text { in Bandung. The results showed } 50 \% \text { of students included in the category of } \\
\text { well-adjustment, and } 50 \% \text { of students included in the category of } \\
\text { maladjustment. Therefore, it is necessary to formulate an appropriate } \\
\text { requirement for guidance and counseling services designed for the } \\
\text { development of boarding school students' self-adjustment. }\end{array}$ \\
\hline
\end{tabular}

KEYWORDS: Adolescents, Single Sex Schools, Social Adjustment.

DOI: 10.30653/001.202042.134

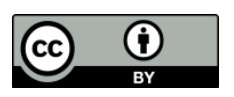

This is an open access article distributed under the terms of the Creative Commons Attribution 4.0 International License, which permits unrestricted use, distribution, and reproduction in any medium, provided the original work is properly cited. ๑) 2020 Nadia Aulia Nadhirah, Ipah Saripah, Esty Noorbaiti Intani.

\section{PENDAHULUAN}

Single sex schools dan coeducational schools menjadi perbincangan bahkan perdebatan yang dilakukan oleh banyak ahli dan peneliti di luar negeri. Berbagai penelitian hingga debat kebijakan internasional dilakukan untuk membahas apakah single sex schools menghasilkan keuntungan akademik dan sosial bagi anak perempuan ataupun laki-laki yang bersekolah di sana. (Smyth, 2010, p. 47). Banyak ahli pendidikan yang percaya bahwa memisahkan siswa menurut gender dapat meningkatkan prestasi akademik (Pahlke, Hyde, \& Allison, 2014, p. 1043). Pada tahun 1990-an perdebatan terus membicarakan tentang jenis sekolah apa yang memberikan hasil yang baik, dan terdapat banyak bukti yang menunjukkan bahwa single sex schools bisa membantu memberikan peningkatan pada prestasi akademik siswa. (Malik, R. 2013, p. 149). Menanggapi hal yang terjadi di luar negeri tentang isu single sex schools, di Indonesia terdapat beberapa lembaga

${ }^{1}$ Corresponding author's address: Program Studi Bimbingan dan Konseling, FIP Universitas Pendidikan Indonesia; Jl. Setiabudi Bandung, Indonesia. Email: nadia.aulia.nadhirah@upi.edu 
pendidikan yang menerapkan sistem single sex schools, diantaranya adalah pesantren yang menerapkan sistem yang sama dengan penempatan siswa sesuai gender dalam satu lingkungan. Penerapan sistem sekolah berdasarkan gender, biasanya dilakukan ditingkat pendidikan menengah.

Siswa pada jenjang menengah termasuk dalam kategori remaja, yang disebut sebagai sebuah transisi dari masa kanak-kanak ke masa dewasa (Rochmania, 2015, p. 2016). Pada masa remaja dijelaskan Hurlock (dalam Nurhusni, 2017, p. 129) bahwa terdapat empat perubahan yang sama dan hampir bersifat universal. Pertama, meningginya emosi yang intensitasnya bergantung pada tingkat perubahan fisik dan psikologis yang terjadi. Kedua, perubahan tubuh, minat dan peran yang diharapkan oleh kelompok sosial, menimbulkan masalah. Ketiga, dengan berubahnya minat dan perilaku, maka nilai-nilai juga berubah. Apa yang ketika masa kanak-kanak dianggap penting, ketika dewasa sudah dianggap tidak penting lagi. Keempat, sebagian besar remaja bersikap ambivalen terhadap setiap perubahan, mereka menginginkan dan menuntut kebebasan namun takut bertangggung jawab akan akibatnya dan meragukan kemampuan mereka untuk mengatasi tanggung jawab tersebut. Perubahan tersebut menjadi tantangan remaja untuk dapat menyesuaikan diri dengan lingkungannya. Oleh karena itu, permasalahan penyesuaian sosial menjadi kajian untuk memfasilitasi perkembangan remaja agar dapat menyelesaikan tugas perkembangannya.

Fenomena perilaku menyimpang di daerah Kendal, diberitakan dalam KR Jogja pada tanggal 14 Januari 2017 terdapat kasus santri tewas (17) karena penganiayaan (Kristianti, 2018, p. 8). Hal tersebut terjadi karena ulah pelaku yang merupakan rekan satu pesantren yang tidak terima karena korban lolos dari hukuman pelanggaran peratuan kedisiplinan, akhirnya terjadi perkelahian hingga korban tewas. Adanya fenomena penyimpangan perilaku tersebut merupakan salah satu masalah pribadi sosial yang ada pada diri santri. Berdasarkan wawancara dengan guru BK, terdapat permasalahan penyesuaian sosial yang terdapat pada single sex schools khususnya di SMA Daarut Tauhid Bandung menunjukkan bahwa banyak siswi yang merasa kurang percaya diri ketika berbicara di depan umum terutama di depan laki-laki, karena tidak terbiasa berinteraksi, terdapat konflik dalam hal pertemanan hingga beberapa siswi terlibat dalam kasus lesbian, menjadi seorang yang pemalu dan bersifat tertutup terhadap orang lain. Fenomena tersebut meresahkan orang dewasa yaitu orang tua dan guru, karena setelah mereka lulus dari sekolah akan melanjukan ke pendidikan yang lebih tinggi atau bekerja yang menuntut untuk dapat memiliki keterampilan penyesuaian sosial yang lebih tinggi.

Evaluasi single sex schools, diantaranya adalah hambatan yang terjadi pada tugas perkembangan remaja. Tugas perkembangan yang terhambat dampak dari lingkungan single sex school ialah penyesuaian sosial. Menurut Hubard (dalam Marianne, 2013, p. 3) menyatakan bahwa minat baru dalam membangun sistem single sex schools untuk mengatasi kebutuhan siswa yang belum tercapai di sekolah reguler. Termasuk di dalamnya pendidikan dan sikap. Jika individu ingin mengembangkan kemampuan dalam penyesuaian sosial maka ia harus menghargai hak orang lain, mampu menciptakan suatu relasi yang sehat dengan orang lain, mengembangkan persahabatan, berperan aktif dalam kegiatan sosial, menghargai nilai-nilai dari hukum-hukum sosial dan tradisi. Apabila prinsip-prinsip ini dilakukan secara konsisten, maka penyesuaian yang baik akan tercapai. Schneider (dalam Maslihah, 2011, p. 107). Namun hal tersebut cenderung mudah dilakukan karena mereka tinggal dalam satu lingkungan pembiasaan dan satu gender yang sama dan individu akan lebih percaya diri karena hal tersebut. 
Sementara studi penelitian Woodward, Fergusson, dan Horwood (1999, p. 2) menyatakan bahwa anak yang bersekolah di single sex schools memiliki prestasi akademik yang lebih tinggi dibandingkan anak yang bersekolah di co-education schools, dengan penjelasan memiliki keberhasilan yang lebih besar dalam ujian sekolah, mendapatkan skor membaca Burt yang lebih tinggi, retensi sekolah yang lebih besar, angka putus sekolah yang rendah dan lebih sedikit terkena pengangguran daripada anak yang bersekolah di co-education schools. Oleh karena itu, perlu ada kajian lebih lanjut mengenai karakteristik remaja dalam penyesuaian sosial pada single sex school.

Remaja yang tidak dapat menyesuaikan diri akan mengembangkan perilaku yang sering disebut "salah suai" atau "maladjustment". Remaja yang tidak dapat melakukan penyesuaian diri yang baik akan mengalami berbagai permasalahan psikologis seperti kecemasan, stress, dan depresi apabila tidak ditangani akan menghambat perkembangannya di masa yang akan datang (Bayu, Saraswati, \& Hartati, 2015, p. 67). Penyesuaian sosial yang baik (well adjusment) diwujudkan dengan menghargai terhadap persamaan dan perbedaan di antara diri sendiri dan orang lain, kemampuan dalam adaptasi sosial, memahami dan menerima kelebihan serta kekurangan seseorang, berpartisipasi dan terlibat dengan orang lain, dan mengembangkan sikap positif di sekolah, komunitas, dan masyarakat. Penyesuaian sosial yang baik didapatkan dari proses belajar atau latihan (Webb, dalam Fornia \& Frame, 2001, p. 386).

Penyesuaian sosial didefinisikan sebagai kemampuan untuk bereaksi secara efektif dan sehat terhadap situasi, realitas dan relasi sosial sehingga tuntutan hidup bermasyarakat dipenuhi dengan cara yang dapat diterima dan memuaskan. (Schneiders,1964, p. 454). Keberhasilan seseorang dalam menyesuaikan diri dengan orang lain dan dengan kelompoknya dapat dilihat dari kemampuan untuk membangun relasi yang sehat dengan orang lain sehingga orang lain akan bersikap positif dan menerimanya dengan baik (Hurlock, 1997, p. 206). Dapat disimpulkan bahwa penyesuaian sosial merupakan kemampuan seseorang untuk menyesuaikan diri secara efektif dan sehat terhadap situasi, realitas, dan relasi sosial sehingga ia dapat diterima dan menerima lingkungan sosial dengan baik.

Jika individu ingin mengembangkan kemampuan dalam penyesuaian sosial maka ia harus menghargai hak orang lain, mampu menciptakan suatu relasi yang sehat dengan orang lain, mengembangkan persahabatan, berperan aktif dalam kegiatan sosial, menghargai nilai-nilai dari hukum-hukum sosial dan tradisi. Apabila prinsip-prinsip ini dilakukan secara konsisten, maka penyesuaian yang baik akan tercapai. Schneider (dalam Maslihah, 2011, p. 107). Dengan demikian penyesuaian sosial sebagai salah satu aspek dari penyesuaian diri individu yang menuju pada kesesuaian antara kebutuhan dirinya dan dengan keadaan lingkungan tempat ia berada dan berinteraksi secara efektif dan efisien. (Susilowati, 2013, p. 101)

Schneiders (1964, p. 51) menyebutkan terdapat beberapa aspek penyesuaian sosial, diantaranya yaitu sebagai berikut: (1) bersikap hormat terhadap guru, kepala sekolah, dan staf sekolah lainnya, (2) berartisipasi aktif dalam kegiatan sekolah, (3) menjalin hubungan persahabatan dengan teman di sekolah, (4) bersikap respek dan mau menerima peraturan sekolah, (5) membantu sekolah dalam merealisasikan tujuan-tujuannya. Dalam aspek penyesuaian sosial dalam ruang lingkup sekolah, terdapat beberapa hal yang harus diperhatikan seperti adanya penerimaan, minat dan partisipasi terhadap fungsi dan aktivitas sekolah serta hubungan yang baik dengan komponen sekolah seperti guru dan teman sebaya. (Fatmala, Zulkarnain, \& Hadiati, 2016, p. 48). 
C. Riodan (dalam Kurniawan, 2016, p. 306) menjelaskan single sex schools merupakan praktek pembelajaran yang membagi siswa-siswinya berdasarkan jenis kelamin, siswa yang berjenis kelamin laki-laki berada dalam satu ruang kelas dengan jenis kelamin yang sama, begitupun sebaliknya. Indikator yang menjadi pola single sex schools mengacu pada pola interaksi, sosialiasasi hubungan pertemanan dan proses pembelajaran. Sementara Amal, Mohamad, dan Eman (2011, p. 176) menjabarkan bahwa single sex schools merupakan praktek pendidikan dimana siswa dan siswinya menghadiri kelas yang terpisah atau bahkan gedung yang terpisah. Praktek pendidikan ini pertama kali dilaksanakan pada pertengahan abad ke dua puluh, khususnya dalam jenjang pendidikan menengah dan pendidikan tinggi. Pendidikan single sex schools banyak dilaksanakan atas dasar anjuran budaya, agama sehingga terlaksana diberbagai bagian dunia. Terdapat satu penelitian yang membuktikan bahwa siswi yang bersekolah di single sex schools memberikan keuntungan yang cukup besar dalam meninggkatkan berbagai aspek perkembangan dalam dirinya. (Jackson, 2012, p. 3).

Dalam segi karakteristik, sejauh ini kebanyakan single sex schools merupakan sekolah swasta maka dalam segi biaya, kebanyakan dari mereka termasuk ke dalam golongan yang kesejahteraannya menengah ke atas, karena hal tersebut memiliki dampak yang besar pada prestasi siswa, hasil sosial akademik dan karir sehingga mampu melanjutkan pendidikan ke single sex schools baik laki-laki maupun perempuan. Anderson dan Delfos (dalam Murray, 2014, p. 9).

Selanjutnya terdapat fenomena yang terjadi dalam penerapan single sex schools yaitu:

1) Agama dan Budaya: dalam konteks agama dan budaya tertentu, anak-anak perempuan orang tua sekolah menengah dan mungkin hanya mengizinkan anak perempuan mereka untuk bersekolah di single sex schools. Orang tua menyekolahkan anaknya sebagai adat atau kebiasaan di keluarganya. Hal tersebut merupakan salah satu alasan untuk jumlah katolik, islam, dan inasia hindu sekolah yang hanya memiliki siswa perempuan atau anak laki-laki

2) Keamanan: orang tua enggan untuk menyekolahkan anaknya di co-educational schools karena kekhawatiran anaknya bergaul dengan laki-laki di luar batas.

3) Jarak: berjalan jarak jauh setiap hari ke sekolah dapat mengekspos gadis-gadis ke ancaman seksual atau serangan fisik. Maka menyekolahkan anaknya di single sex schools dengan sistem asrama akan meminimalisir tingkat kriminalitas tersebut.

4) Pilihan kedua dalam pendidikan: single sex schools bisa menjadi pilihan kebijakan yang layak bagi anak perempuan yang putus sekolah dan terlalu tua untuk merasa nyaman secara sosial untuk masuk kembali ke kelas formal. (UNESCO, 2007, p. 2)

Hasil kajian Schneiders (1964, p. 459), siswa yang tidak dapat melakukan penyesuaian sosial dengan baik ditandai dengan: 1) ketidakmampuan mengatasi konflik yang dihadapinya atau tidak menemukan cara-cara yang tepat untuk mengatasi masalah atau tuntutan dari lingkungan, sehingga hal tersebut menimbulkan rasa frustrasi pada dirinya; 2) tidak mampu membangun hubungan baik dengan orang lain;3) sulit dipercaya dan diterima oleh orang lain atau lingkungannya. Schneider (dalam Maslihah, 2011, p. 108) menyatakan bahwa dalam diri individu terdapat berbagai faktor yang mempengaruhi penyesuaian sosial, yaitu:

1) Kondisi Fisik dan faktor-faktor yang mempengaruhinya, meliputi hereditas, konstitusi fisik, kesehatan, sistem syaraf, kelenjar, dan otot. 
2) Perkembangan dan kematangan, khususnya intelektual, sosial, moral, dan emosi.

3) Kondisi psikologis, meliputi pengalaman, proses belajar, pembiasaan, frustasi, dan konflik.

4) Kondisi lingkungan, khususnya lingkungan rumah, keluarga, sekolah, dan masyarakat.

5) Faktor kebudayaan, termasuk agama.

\section{METODE}

Metode penelitian menggunakan kuantitatif dengan melakukan survei. Penelitian dilakukan dengan menyebar angket penyesuaian sosial yang diadaptasi dari skripsi Della (2019) selain itu dilakukan wawancara dengan guru BK dan beberapa siswi SMA Daarut Tauhid. Subjek penelitian ini adalah remaja single sex schools kelas XII di SMA Daarut Tauhid Bandung dengan sampel penelitian berjumlah 26 orang.

\section{HASIL DAN PEMBAHASAN}

Hasil penelitian dikategorikan menjadi dua yaitu well-adjustment dan maladjustment. Data tersebut dapat dilihat dalam table sebagai berikut.

Tabel 1. Interval dari Tiap Kategori Data Hasil Penelitian

\begin{tabular}{llll}
\hline Interval & Kategori & Frekuensi & $\%$ \\
\hline$\geq 232,5$ & Well-adjustment & 13 & $50 \%$ \\
\hline$<232,5$ & Maladjustment & 13 & $50 \%$ \\
\hline
\end{tabular}

Penyesuaian sosial, adjustment atau maladjustment atau penyesuaian sosial yang baik atau penyesuaian diri yang bermasalah adalah taraf sejauh mana seseorang terbebas dari berbagai jenis tekanan emosi dan/atau terbelit oleh kebiasaan bertingkah laku yang menimbulkan gangguan terhadap kesejahteraan pribadinya maupun terhadap relasinya dengan orang lain sehingga pada akhirnya juga mengganggu kesejahteraan pribadinya. Supratiknya (2014, p. 106) menjelaskan penyesuaian sosial yang bermasalah berkisar antara kecenderungan disruptif atau merusak atau mengganggu mulai dari yang relatif ringan seperti neurosis sampai yang relatif berat seperti psikosis. Lawannya adalah penyesuaian sosial yang baik yang ditandai antara lain oleh perasaan sejahtera (subjective well-being) dan keefektivan dalam menjalankan aneka tugas kehidupan sehari-hari (pribadi yang efektif).

Dalam konteks pendidikan di sekolah, siswa yang dapat melakukan penyesuaian sosial yang baik ditandai dengan: 1) mampu memahami dan bereaksi terhadap dirinya dan lingkungannya dengan cara yang matang, efisien, sehat, dan memuaskan; 2) dapat menerima lingkungannya serta mendapatkan penerimaan yang baik dari lingkungannya; 3) dapat menghargai lingkungannya; 4) memiliki kehangatan dan keterbukaan; 5) menunjukkan dirinya apa adanya (Cross, Coleman, \& Stewart, 1995, pp. 183-184).

Hasil penelitian secara aspek dijelaskan bahwa aspek hormat terhadap kepala sekolah, guru, dan staf sekolah lainnya, 69,2\% dengan frekuensi 18 orang berada pada kategori maladujustment, dan 30,8\% dengan frekuensi 8 berada pada kategori well- 
adjustment. Artinya kebanyakan siswa belum mampu menjalin hubungan yang baik dengan pemimpin sekolah guru, konselor, dan personel sekolah lainnya; belum mampu bertutur kata dengan sopan dan santun; dan masih belum menjaga sikap ketika bertemu dengan pemimpin sekolah guru, konselor, dan personel sekolah lainnya.

Aspek berartisipasi aktif dalam kegiatan sekolah. 69,2\% dengan frekuensi 18 orang berada pada kategori maladjustmet dan 30,8\% dengan frekuensi 8 orang berada pada kategori well-adjustment. Artinya kebanyakan siswa masih kurang memiliki minat dan partisipasi untuk mengikuti kegiatan belajar mengajar (KBM); dan kurang memiliki minat dan partisipasi untuk mengikuti kegiatan sekolah di luar pembelajaran.

Aspek menjalin hubungan persahabatan dengan teman di sekolah, $50 \%$ dengan frekuensi 13 orang seimbang berada pada kategori well-adjustment dan maladjusment. Artinya dalam satu kelas siswa sudah menerima kondisi fisik, psikologis, status sosial, dan status ekonomi keluarga teman apa adanya; diterima dan diakui dalam lingkungan pergaulan teman sebaya; memiliki pengendalian emosi saat terlibat perselisihan dengan teman; dan mampu mempertahankan hubungan persahabatan, tapi masih terdapat pula siswa yang belum mampu melakuakan hal tersebut. Lingkungan teman sebaya merupakan satu kelompok yang baru, yang memiliki ciri, norma, kebiasaan yang jauh berbeda dengan apa yang ada dalam lingkungan keluarga. Dalam hal ini individu dituntut untuk memiliki kemampuan pertama dan baru dalam menyesuaikan diri yang dapat dijadikan dasar dalam hubungan sosial yang lebih luas. (Gunarsa, 1982, p. 131)

Aspek bersikap respek dan mau menerima peraturan sekolah. 57,7\% dengan frekuensi 15 orang berada pada kategori maladjustment dan 42,3\% dengan frekuensi 11 berada pada kategori well-adjusmtent. Artinya lebih banyak siswa memiliki kesadaran akan pentingnya peraturan sekolah; dan mematuhi peraturan sekolah secara baik dan penuh kesadaran. Jika individu ingin mengembangkan kemampuan dalam penyesuaian sosial maka ia harus menghargai hak orang lain, mampu menciptakan suatu relasi yang sehat dengan orang lain, mengembangkan persahabatan, berperan aktif dalam kegiatan sosial, menghargai nilai-nilai dari hukum-hukum sosial dan tradisi. Apabila prinsipprinsip ini dilakukan secara konsisten, maka penyesuaian yang baik akan tercapai. Schneider (dalam Muslihah, 2011, p. 107).

Aspek membantu sekolah dalam merealisasikan tujuan-tujuannya. 61,5\% dengan frekuensi 16 orang berada pada kategori maladjustment, 38,5\% dengan frekuensi 10 orang berada pada kategori well-adjustment. Artinya masih banyak siswa yang kurang mendukung kegiatan belajar mengajar (KBM); dan melaksanakan kewajiban sebagai peserta didik.

Hasil kajian Schneiders (1964, p. 459), siswa yang tidak dapat melakukan penyesuaian sosial dengan baik ditandai dengan ketidakmampuan mengatasi konflik yang dihadapinya atau tidak menemukan cara-cara yang tepat untuk mengatasi masalah atau tuntutan dari lingkungan, sehingga hal tersebut menimbulkan rasa frustrasi pada dirinya, tidak mampu membangun hubungan baik dengan orang lain; sulit dipercaya dan diterima oleh orang lain atau lingkungannya. Untuk mencapai tujuan dari pola sosialisasi dewasa, remaja harus membuat banyak penyesuaian baru. Yang terpenting dan tersulit adalh penyesuain diri dengan meningkatnya pengaruh kelompok sebaya, perubahan dalam perilaku sosial, pengelompokan sosial baru, nilai-nilai baru dalam seleksi persahabatan, nilai-nilai baru dalam dukungan dan penolakan sosial, dan nilai-nilai baru dalam seleksi pemimpin (Hurlock, 1980, p. 213). 
Remaja dapat dikatakan dapat menyesuaikan diri dengan baik (well adjustment) apabila mampu melakukan respon-respon yang matang, efisien, memuaskan dan sehat. Efisien yang dimaksud adalah ketika remaja mampu melakukan respon yang memanfaatkan waktu semaksimal mungkin dengan tenaga yang sedikit (Ali \& Asrori, 2012, p. 85). Bagi remaja menurut Nurdin (dalam Susilowati, 2013, p. 105) yang tersulit adalah melakukan penyesuaian diri dengan meningkatkan pengaruh kelompok sebaya, perubahan dalam perilaku sosial, pengelompokkan sosial yang baru, menyesuaikan dengan nilai-nilai baru dalam seleksi persahabatan, dukungan sosial dan penolakan sosial serta seleksi dalam kepemimpinan dalam kelompok sosial.

Upaya pendidikan dalam mengembangkan sistem penyesuaian sosial dapat dilakukan dengan menciptakan sistuasi yang penuh keakraban dimana dalam situasi tersebut terwujud nilai-nilai hidup dalam bentuk perilaku yang dapat memengaruhi dan mendorong anak berbuat atau kesadaran dan kemauannya sendiri (Kartadinata, 2011, p. 33). Dalam hal ini layanan bimbingan dan konseling memiliki fungsi penyesuaian yaitu upaya membantu terciptanya keharmonisan antara individu dan lingkungan tempat kehidupannya, baik lingkungan pendidikan, keluarga, karir dan masyarakat pada umumnya.

Pengembangan penyesuaian sosial dapat dilakukan pula melalui layanan dasar. Layanan tersebut bertujuan agar membantu siswa agar memperoleh perkembangan yang normal, memiliki mental yang sehat dan memperoleh keterampilan dasar dalam hidupnya. (Yusuf \& Nurihsan, 2011, p. 26). Ketidakmampuan untuk menyesuaikan diri sering kali menjerumuskan individu pada perilaku negatif atau salah suai (maladjustment). Dalam hal keberadaan bimbingan dan konseling bertanggungjawab untuk memberikan layanan bantuan kepada individu yang sedang mengalami krisis atau masalah melalui layanan responsif.

Upaya yang dapat dilakukan untuk mengembangkan penyesuaian dapat dilakukan melalui empat metode pengangan. Schneiders (1964, p. 534) membedakan empat dasar penanganan sebagai berikut:

1) Remidial, mengatasi kesulitan yang melibatkan beberapa kekurngan yang dapat diatasi dengan instruksi atau pelatihan.

2) Informasi atau nasihat, mengatasi masalah atau kesulitan yang tidak melibatkan kegagalan psikologis secara berkala.

3) Psikoterapi, mengatasi maslaah gangguan mental atau gangguan kepribadian.

4) Medis, mengatasi masalah yang berat dengan penggunaan atau manipulasi untuk faktor psikologis.

\section{SIMPULAN}

Berdasarkan hasil penelitian dan pembahasan, dapat disimpulkan penyesuaian sosial remaja single sex schools di SMA Daarut Tauhid Bandung Tahun Ajaran 2019/2020 $50 \%$ dengan frekuensi 13 orang termasuk dalam kategori tinggi (well-adjustment), dan 50\% responden dengan frekuensi 13 orang termasuk dalam kategori rendah (maladajustment). Artinya, perlu ada upaya layanan bimbingan dan konseling untuk pengembangan dan perbaikan penyesuaian diri siswa. Layanan pengembangan dapat dilakukan melalui layanan dasar sementara layanan perbaikan penyesuaian diri dapat dilakukan melalui layanan responsif yang disesuaikan dengan kebutuhan peserta didik. 


\section{REFERENSI}

Ali, M. \& Asrori, M. (2012). Psikologi remaja perkembangan peserta didik. Jakarta: Bumi Aksara.

Amal, K. I., Mohamad, A. H. O., \& Eman, D. S. (2011). Coeducation versus single sex education: Impact on self esteem and academic achievements among nursing' students. American Science, 7(12). 176-184.

Bayu, B. L., Saraswati, S., \& Hartati, M. T. S. (2015). Mengatasi perilaku maladjustment melalui konseling behavioristik dengan teknik pengkondisian operan. Indonesian Journal of Guidance and Counseling: Theory and Application, 4(1), 66-71.

Cross, T. L., Coleman, L. J., \& Stewart, R. A. (1995). Psychosocial diversity among gifted adolescents: An exploratory study of two groups. Roeper Review, 17(3), 181-185.

Fatmala, K., Zulkarnain, \& Hadiati, L. (2016). Efektivitas Sosial Skill Training (SST) dalam meningkatkan kemampuan penyesuaian sosial siswa SD kelas akselerasi. Psikologia: Jurnal Pemikiran \& Penelitian Psikologi, 11(1). 47-60.

Fitri, Y. A., Firman, \& Karneli, Y. (2016). efektivitas layanan informasi dengan pendekatan role playing untuk meningkatkan penyesuaian sosial siswa kelas VII SMPN 3 Batusangkar. Konselor: Jurnal Ilmiah Konseling, 1(2), 1-7.

Fornia, G. L., \& Frame, M. W. (2001). The social and emotional needs of gifted children: Implications for family counseling. The Family Journal: Counseling and Therapy for Couples and Families, 9(4), 384-390.

Gerungan, H. A. (1988). Psikologi sosial. Jakarta: Eresco.

Havighurst, R. J. (1961). Human development and education. New York: Longmans Green and Co.

Hurlock, E. B. (1997). Perkembangan individu (Alih Bahasa: M. Tjandrasa \& M. Zarkasih). Jakarta: Penerbit Erlangga.

Pahlke, E., Hyde, J. S., \& Allison, C. M. (2014). The effects of single-sex compared with coeducational schooling on students' performance and attitudes: A meta-analysis. Psychological Bulletin, 140(4), 1042.

Istarani. (2012). Model pembelajaran inovatif. Medan: Media Persada.

Jackson, C. K. (2012). Single-sex schools, student achievement, and course selection: Evidence from rule-based student assignments in Trinidad and Tobago. Journal of Public Economics, 96(1-2), 173-187. 
Kurniawan, E. (2017). Pengaruh pelaksanaan pembelajaran pai dengan pola single sex education terhadap motivasi belajar peserta didik di MTs al-Mudzakkirin Argapura Majalengka Tahun Akademi 2016/2017. In Prosiding Pendidikan Agama Islam (pp. 304309). Bandung: Unisba.

Kristianti, M. (2018). Perilaku menyimpang kaum santri, studi lingkungan pondok pesantren Nurul Ummahat Kotagede, Yogyakarta. Skripsi. Universitas Islam Negeri Sunan Kalijaga: Yogyakarta.

Malik, R. A. (2013). Differential effects of single sex versus coed education on the personality development of primary school students. Pakistan Journal of Social Sciences (PJSS), 33(1), 149-162.

Maslihah, S. (2011). Studi tentang hubungan dukungan sosial, penyesuaian sosial di lingkungan sekolah dan prestasi akademik siswa SMPIT Assyfa Boarding School Subang Jawa Barat. Jurnal Psikologi, 10(2), 103-114.

Murray, G. (2014). The single sex $v$ coeducation debate and the experience of schools that change status. Armidale, NSW: The Armidale School Australia.

Nurhusni, P. (2017). Profil penyesuaian sosial remaja yang mengalami kecanduan mengakses facebook. Indonesia Journal of Education Counseling, 1(2). 129-144.

Rochmania, B. K. (2015). Sikap Remaja Putri dalam Menghadapi Perubahan Fisik Masa Pubertas. Jurnal Promkes: The Indonesian Journal of Health Promotion and Health Education, 3(2), 206-217.

Schneiders, A. A. (1964). Personal adjustment and mental health. New York, Hoolt, Rinehart and Winston.

Smyth, E. (2010). Single-sex education: What does research tell us?. Revue française de pédagogie. Recherches en Éducation, 171, 47-58.

Sugiyono. (2013). Metode penelitian pendidikan pendekatan kuantitatif, kualitatif, dan RED. Bandung: Alfabeta.

Susilowati, E. (2013). Kematangan emosi dengan penyesuaian sosial pada siswa akselerasi tingkat SMP. Jurnal Online Psikologi, 1(1), 101-113.

Supratiknya, A. (2014). Pengukuran psikologis. Yogyakarta: Penerbit Universitas Sanata Dharma.

Ulfah, M. (2012). Program bimbingan dan konseling pribadi sosial untuk meningkatkan kemampuan penyesuaian diri siswa terhadap keragaman budaya. Bandung: Universitas Pendidikan Indonesia:

UNESCO. (2007). Single sex schools for girls and gender quality in education. Bangkok: UNESCO Asia and Pasific Regional Bureau for Education. 
Woodward, L. J., Fergusson, D. M., \& Horwood, L. J. (1999). Effects of single-sex and coeducational secondary schooling on children's academic achievement. Australian Journal of Education, 43(2), 142-156.

Yusuf, S., \& Nurihsan, J. (2011). Teori kepribadian. Bandung: Remaja Rosdakarya. 